\title{
Uma "impressão histórico-bibliográfica" sobre Comenius: da cultura à cultura impressa na obra comeniana
}

\author{
A "historical bibliographical impression" of Comenius: from culture to print culture in the \\ Comenius's book
}

\author{
Roge Cavalcante da Silva \\ Graduação em Biblioteconomia pela Universidade Federal do Estado do Rio de Janeiro - UNIRIO. \\ E-mail: cavalcanteroge@gmail.com
}

\author{
Gustavo Silva Saldanha \\ Doutor em Ciência da Informação pelo PPGCI IBICT UFRJ. \\ Pesquisador Adjunto do Instituto Brasileiro de Informação em Ciência e Tecnologia - IBICT e Professor \\ Adjunto da Universidade Federal do Estado do Rio de Janeiro - UNIRIO. \\ E-mail: gustavosaldanha@ibict.br
}

\section{Resumo}

Este estudo, orientado para a filosofia do livro e seu impacto no pensamento pedagógico de Comenius, integra o projeto "Epistemologia histórica do pensamento biblioteconômico-informacional: a trama da linguagem entre instituições, conceitos, artefatos e intersujeitos", desenvolvido no contexto da Escola de Biblioteconomia da Universidade Federal do Estado do Rio de Janeiro. O recorte de pesquisa se aproxima dos debates sobre a fundamentação do campo informacional, porém explorando não apenas suas demandas filosóficas, mas incluindo dois eixos co-centrais: a) uma epistemologia histórica, interessada em um olhar sobre os modos como as ideias se estabelecem no tempo-espaço em mutação, e b) uma filosofia da cultura, orientada para o posicionamento dos objetos de estudo, abarcando os conceitos, com integrantes de dimensões construídas e disputadas dentro das dinâmicas culturais. O referencial teórico estabelece-se a partir de fontes oriundas da Biblioteconomia \& Ciência da Informação, Educação e História (mais especificamente, os estudos do domínio de História do Livro). Como caracterização metodológica, realiza-se estudo histórico-bibliográfico, com foco no pensamento bibliológico, com vistas à compreensão das margens de influência da cultura impressa no pensamento pedagógico de Johann Amós Comenius (1592-1670). Parte do resultado de um estudo mais amplo, de natureza dupla (histórica e empíricoconceitual), o enfoque geral do estudo procurou demarcar os indícios manifestos da cultura impressa na elaboração de conceitos da Filosofia da Educação presentes na obra maior de Comenius, a Didactica Magna (1657). As diretivas conclusivas procuram comprovar os modos teóricos de influência de uma filosofia do livro transformada por impactos socioculturais.

Palavras-chave: Livro. Filosofia do Livro. Comenius. Cultura Impressa.

\begin{abstract}
The research is part of the project "Historical Epistemology of library and informacion science thought: the language web between institutions, concepts, artifacts and inter-subjects", developed in the context of the Library Science School from the Federal University of the State of Rio de Janeiro (Unirio). The study includes two main axes: a) a historical epistemology, interested in a look at the ways in which the ideas are established in the changing time-space, and b) a philosophy of culture, oriented for the concepts and the built of the cultural dynamics. The theoretical framework is established from originating sources of the fields Library \& Information Science, Education and History (more specifically, studies of the History of Book domain). As a methodological approach, carried out historical-bibliographical study, focusing on bibliológico thought, with a view to understanding the cultural margins of influence of print culture in pedagogical thinking of Johann Amos Comenius (1592-1670). Part of the results of a larger study, the general approach of the study sought to demarcate the clear indications of print culture in the development of concepts of Philosophy of Education present in the greatest work of Comenius, the Didactica Magna, in 1657. The conclusive directives seek to prove the theoretical modes of influence of a Book Philosophy and your the sociocultural impact on modern thought.
\end{abstract}

Keywords: Book. Book Philosophy. Comunius. Print culture.

InCID: R. Ci. Inf. e Doc., Ribeirão Preto, v. 8, n. 1, p. 4-23, mar./ago. 2017.

DOI: 10.11606/issn.2178-2075.v8i1p4-23 


\section{Introdução}

A presente reflexão é resultado de um estudo histórico-bibliográfico, com foco no pensamento bibliológico, com vistas à compreensão das margens culturais de influência da cultura impressa no pensamento pedagógico de Johann Amós Comenius (1592-1670). Parte do resultado de um estudo mais amplo, de natureza dupla (histórica e empírico-conceitual), o enfoque geral do estudo procurou demarcar os indícios manifestos da cultura impressa na elaboração de conceitos da Filosofia da Educação presentes na obra maior de Comenius, a Didactica Magna, de 1657. Em outros termos, trata-se de compreender como a "ciência bibliológica", ou a Bibliologia, segundo as visões de Peignot (1802a,b) e Otlet (1934), são frutos de, e refletem a construção simbólica do conceito de livro na e para a Modernidade.

Integrando um projeto mais amplo - "Epistemologia histórica do pensamento biblioteconômico-informacional: a trama da linguagem entre instituições, conceitos, artefatos e intersujeitos", desenvolvido no contexto da Escola de Biblioteconomia da Universidade Federal do Estado do Rio de Janeiro - o estudo aborda os debates sobre a fundamentação do campo informacional, porém explorando não apenas suas demandas filosóficas, mas incluindo dois eixos co-centrais: a) uma epistemologia histórica, interessada em um olhar sobre os modos como as ideias se estabelecem no tempo-espaço em mutação, e b) uma filosofia da cultura, orientada para o posicionamento dos objetos de estudo, incluindo os conceitos, com integrantes de dimensões construídas e disputadas dentro das dinâmicas culturais. Encerra-se aqui, pois, o objeto de estudo ora discutido, ou seja, uma produção conceitual que tem como marca uma filosofia do livro transformada por impactos socioculturais no pensamento moderno. Relacionamos ainda, no estudo, as demandas de aproximação disciplinar entre Biblioteconomia \& Ciência da Informação, Educação e História (mais especificamente, os estudos do domínio de História do Livro).

A imprensa de Gutenberg, constituída a partir 1455, é assunto central no âmbito da História do Livro. Peter Burke (2002) explorou esse universo encontrando semelhanças históricas de âmbito informacional, de modo que hoje sabemos que uma dada "explosão informacional" não foi um fenômeno unicamente dos séculos XIX ou XX. Sua pesquisa revelou que nos primórdios da modernidade já era possível se perder em meio à "floresta de livros", um fenômeno gerado pela invenção da imprensa de Gutenberg. É no contexto do desdobramento de uma cultura pós-gutenbergiana, em que conhecimento e registros do conhecimento 
(estruturalmente "códices vegetais") se co-fundem, que identificamos a personagem de nossa investigação, Johann Amós Comenius.

Comenius foi um erudito do século XVII, que propôs a distribuição das matérias escolares, a separação das turmas de acordo com a faixa etária, pensou a organização dos horários de aula e se preocupou com a preparação dos materiais didáticos quando a Modernidade despontava. Gadotti (2003) liga sua Didática à Modernidade na medida em o coloca ao lado de Francis Bacon, com um realismo filosófico, que apreende do mundo natural e do mundo artificial modelos aplicáveis à Educação, resultando na sistematização das práticas educativas. Tal configuração biográfico-epistêmica coloca Comenius como um personagem fundamental para a reflexão no campo biblioteconômico-informacional, assim como Bacon.

Os conhecimentos construídos por Comenius no âmbito da Educação reverberaram no tempo-espaço. Comenius foi lembrado na conferência de 1956 da UNESCO, em Nova Delhi, onde foi deliberada a publicação de suas obras, considerando Comenius um dos primeiros propagadores das ideias da organização. Com seu foco na educação para todos, Comenius se insere no debate da democratização do ensino. Na década de 1990 estudiosos da educação, tais como Gasparin (1998), Cauly (1995), Kuleza (1992) e Covello (1999) revisitaram os conceitos da pedagogia comeniana com o objetivo de recuperar seus aspectos fundamentais, e, recentemente, em 2011, Kulesza traduziu uma obra original de Comenius pouco explorada no país, a Schola Infantiae. Comenius está, ainda, entre os clássicos da educação, e, para alguns, como Cauly (1995), pode ser chamado de "pai da pedagogia moderna" - enquanto Gasparin (1998) prefere tratar Comenius como um emergente da Modernidade. Em todo caso, no âmbito da Filosofia e da História da Educação Comenius é comparado a Galileu ou a Descartes, com um conjunto de conceitos e teorias que contribuem para a construção do corpus de uma área.

A partir da expressão biográfico-teórica comeniana, o fato que nos interessa diretamente é a relação entre o raciocínio/argumento discursivo de Comenius e a cultura impressa, entre a sua obra nuclear, a Didactica Magna (1657), e a tipografia. A relação é reconhecida após nossa aproximação à Filosofia da Educação: Quando Comenius recorreu à ordem do mundo artificial para elaborar uma pedagogia, encontrou na tipografia o imaginário conceitual que lhe atendia objetivamente. Em certo trecho da Didactica Magna (COMENIUS, 1985, XXVII §7) ele argumenta "O papel são os alunos, em cujos espíritos devem ser impressos os caracteres das ciências [...]Os tipos são os livros [...] A tinta é a viva voz do professor que transfere o significado das coisas [...]”. A partir disso, lançamos o olhar sobre Comenius, tendo como 
aportes a influência da cultura impressa, identificada pelas revisões de Burke (2002), e apropriadas por Peignot (1802a,b) e Otlet (1934), que recaem sobre a noção de bibliologia, do Biblion, pensando no campo da Documentação e da Ciência da Informação a partir de seus aspectos materiais, técnicos, e sociais no tempo-espaço. Trata-se de pensar a Bibliologia, ciência do livro na linguagem peignotiana-otletiana, como não apenas o desdobramento da Modernidade, mas como uma de suas premissas.

No plano metodológico do estudo, buscamos a "promoção" do que Freire (2013) chamou de "curiosidade epistemológica", que se torna, por assim dizer, "epistemológica" na medida em se desenvolve a criticidade e rigor metodológico. A pesquisa orientada pela "curiosidade epistemológica" formula perguntas sobre os objetos, indaga, questiona, constata, verifica, comunica e educa. Desse modo, a questão de pesquisa que nos norteia é: Considerando que em diferentes passagens da obra Didactica Magna (1657), Comenius abordou a tipografia para elucidar seu pensamento pedagógico, comparando o ensino com a técnica de impressão de livros, em que medida podemos compreender estas relações como fruto da influência da cultura impressa sobre o pensamento comeniano?

Para pesquisar esse problema sob a ótica bibliológica foi-nos necessário construir sustentação teórica, relacionando a vida e obra de Comenius e o pensamento históricobibliológico (o lugar do livro na história e a história do livro em suas evidências centrais). Posteriormente procuramos avançar nas entrelinhas de uma episteme introduzida por Comenius e sua relação com a Bibliologia. Buscamos aqui uma fundamentação para novos estudos relacionados a Didática de Comenius e a cultura impressa no escopo bibliológico.

Reconhecemos aqui que "cultura impressa" é um termo abrangente, que pode ser usado para se referir aos vários modos de vida relativos à imprensa. $\mathrm{O}$ termo pode indicar os processos de fabricação do livro até seu destino final, a leitura e os mais diversos gestos e performances de apropriação do artefato. Visto isso, foi necessário limitar a pesquisa ao processo de impressão, a disseminação deste processo, e a publicação dos livros.

Os estudos em História do Livro mostraram que a cultura imprensa se constituiu a partir de práticas, como por exemplo, a escrita inventada na Antiguidade e o livro medieval. Contudo, apesar das heranças culturais, a imprensa teve a novidade dos tipos móveis inventados por Gutenberg e aos poucos o livro impresso foi adquirindo características próprias de sua cultura, que se espalhou rapidamente pela Europa durante o século XV. No século XVI os livros 
impressos contribuíram objetivamente para o desenvolvimento da Modernidade, ao fazer circular os escritos da Reforma e as ideias científicas. Assim compreendemos que a cultura impressa se tornou parte da sociedade durante os primórdios da Europa Moderna, "imprimindo" seus modos de ser e acontecer em espíritos como o de Comenius.

A partir da biografia de Johann Amós Comenius (1592-1670) conhecemos que o autor da Didactica Magna nasceu na Morávia (atual República Checa), estudou nas universidades alemãs de Herbon e Heidelberg, e iniciou sua carreira como professor de latim nas escolas de Prerov e Fulnek, ambas sob a influência dos Irmãos Morávios, mas por causa da Guerra dos Trinta Anos teve que abandonar o trabalho e viver exilado. Durante o exilio na Boêmia, Comenius começa a escrever, em 1627, a Didactica Checa, sendo que esta mais se transformara na Didactica Magna. Impossibilitado de retornar a Morávia, Comenius envolve-se na reforma de escolas na Inglaterra e Suécia, passa pela na Holanda, aonde chega a ter contato com Descartes. Comenius ainda escreveu, em 1653, outra importante obra, "O mundo ilustrado", considerado um marco do livro didático ilustrado. A ausência de organização nas escolas por onde passou, levou Comenius a propor um método educacional, o "tratado da arte universal de ensinar tudo a todos", o que fez dele um importante teórico da Educação.

\section{Da cultura à cultura do registro gráfico: diálogos terminológicos}

No território das dinâmicas terminológicas estabelecemos diálogos entre conceitos ou noções que convergem na visão histórico-bibliológica dos registros gráficos, a partir de obras que são referências para os estudos da História Cultural do livro, da História e Filosofia da Educação, e da didática comeniana. À busca pela compreensão do termo "cultura impressa", optamos por discutir, não exaustivamente, o significado do termo "cultura". Os resultados da reflexão foram somados à noção de cultura apresentada pelos autores da História do Livro, a fim de esboçar norteadores para o uso do termo "cultura impressa". Para apresentar principalmente a cultura de fabricação do livro e a publicitação do objeto impresso, recorremos especialmente à Douglas McMurtrie (1982), Fredéric Barbier (2008), Wilson Martins (2001) e Lucien Febvre \& Henri-Jean Martin (1992).

McMurtrie (1982) introduziu os estudos do livro no início do século XX ao escrevem “O livro: impressão e fabrico". Tivemos acesso a esta obra na $3^{\text {a }}$ edição da Fundação Calouste Gulbenkian. A obra “O aparecimento do livro” de Lucien Febvre \& Henri-Jean Martin (1992) 
também está entre as fontes consultadas, atentada aqui especialmente em razão de aspectos sociais relativos ao surgimento do livro impresso. Outra fonte, Frédéric Barbier, (2008), é adotado para o domínio vasto, aberto e povoado de interpretações da "História do Livro", na qual, traça um panorama histórico-social sobre o livro, a começar pelas formas primitivas da escrita até o livro moderno. Entre as referências nacionais se coloca o historiador e crítico literário Wilson Martins (2001), a partir de sua obra “A palavra escrita”.

A vida e obra de Comenius é apresentada a partir da extensa biografia escrita pelo pesquisador francês Oliver Cauly (1995), que procurou indicar Comenius como a "pai da pedagogia moderna". Kelusza (1992) escreveu a obra "Comenius: a perspectiva da utopia em educação", como resultado sua tese de doutorado pela Faculdade em Educação da Universidade de Campinas. Nesse trabalho ele recorreu a documentos salvaguardados pelo museu de Comenius, na República Checa, vindo a ser uma importante fonte biográfica sobre Comenius.

\section{Cultura impressa: a construção de um tempo e de um tecnoespaço}

Como antecipado, em razão do objeto de estudo e de sua contextualização sócio histórico, foi necessário buscar norteadores para o termo "cultura impressa". A intenção foi encontrar parâmetros para orientar o discurso do que se nomeia de cultura impressa. Para os gregos, cultura significava "formação do homem, sua melhoria e seu refinamento". Mas na contemporaneidade os filósofos e antropólogos consideram que cultura é:

Um conjunto dos modos de vida criados, adquiridos e transmitidos de uma geração para a outra, entre os membros de determinada sociedade; nesse caso, cultura também pode aparecer em equivalência ao termo 'civilização'. (ABBAGNANO, 2007, p. 225).

Esse significado mais recente considera que a cultura se desenvolve a partir da criatividade humana. Segundo Huisman (1966), a técnica, arte, religião e a ciência são resultados da ação humana; são manifestações culturais de ordem material ou intelectual.

A priori, a historiografia dos registros gráficos parece acolher a noção contemporânea de cultura. O livro, tal como tradicionalmente se narra, surge no conjunto das ações humanas criativas e transformadoras. Em resumo: os povos antigos da Mesopotâmia criavam placas de argila para usar como suporte de escrita, e, sabe-se ainda, que os antigos egípcios eram mestres em transformar o caule do papiro em fitas apropriadas para escrita. Na Idade Média os monges empregavam técnicas para fabricar o códice a partir da pele de animais. Sobre a imprensa de 
Gutenberg se pode dizer que a criatividade estava na habilidade de reunir a antiga máquina de prensar aos tipos móveis feito em metal maleável, algo que Douglas McMurtrie (1982, p.134), chamou em sua narrativa de "o poder criador de síntese".

Estudos bibliológico-historiográficos emergentes contribuem para o mesmo entendimento. Quando Robert Darnton (1990) propôs responder a questão "o que é a história do livro?" deixou transparecer que é objetivo da disciplina compreender o livro incorporado à dinâmica sócio comunicacional capaz de afetar o comportamento humano, ou seja, assenta-se a ideia do livro como elemento participante dos modos de viver socialmente.

Histoire du livre na França, Geschichte des Buchwesens na Alemanha, history of books ou of the book nos países de língua inglesa - o nome varia de lugar para lugar, mas por toda parte ela está sendo reconhecida como uma nova disciplina importante. Até se poderia chamar de história social e cultural da comunicação impressa, se não fosse um nome tão comprido, pois sua finalidade é entender como as ideias eram transmitidas por vias impressas e como o contato com a palavra impressa afetou o pensamento e comportamento da humanidade nos últimos quinhentos anos (DARNTON, 1990, p. 65)

Elizabeth Eisenstein (1998) empregou o termo "cultura imprensa", que ora buscamos nortear, considerando como ponto de partida objetos (tipos, tinta, prensa, etc) que, reunidos, constituem o processo de fabricação do livro imprenso:

Utilizamos o termo 'imprensa' como um rótulo conveniente, como se fosse uma expressão abreviada para nos referirmos a um conglomerado de inovações (ocasionando o uso de tipos de metal móveis, tinta à base de óleo, prensa de madeira manual, e assim por diante) (EISENSTEIN, 1998, p. 28).

Ao que se percebe, a autora conjuga a dimensão material e intelectual do processo criativo humano. Estamos diante de uma "imprensa" resultante da técnica: como Barbier (2008) acredita, os tipos móveis surgiram, provavelmente, da habilidade de Gutenberg com o metal, desenvolvida no momento em que trabalhou no ofício de ourives, e, no referente à prensa, diz remontar a antiga técnica de prensar uvas. Os objetos, os artifícios, são matéria que coexistem a técnica, a habilidade, ao raciocínio.

Apesar dessa consideração, é adequado destacar que o trabalho de Eisenstein (1998) não se voltou especificamente para os modos de produção do livro impresso, para a técnica ou para a apropriação de materiais, ela se propôs observar as características da cultura impressa. Eisenstein (1998) lançou seu olhar para a disseminação, padronização, reorganização do layout, duplicação dos textos, e outras características que segundo a autora seriam próprias da cultura impressa. 
Ante ao conhecimento a priori e a historiografia mais recente de Darnton (1990) e Eisenstein (1998), percebemos que o termo "cultura imprensa" possui amplo significado, que remete a noção de cultura como um conjunto de modos de vida. Pode ser a cultura comunicacional do texto impresso modificante de comportamentos, artifícios e técnicas de manipulação de materiais e execução de processo. Abordar a totalidade dessa cultura seria tarefa árdua. Ao que nos cabe, trataremos a cultura impressa como o conjunto de modos relativos à fabricação do livro impresso por meio de artifícios: tipos móveis, tinta, prensa, etc. Embora conscientes das características da cultura impressa, todas elas seriam demasiada ocupação para a pesquisa em questão, entretanto não é pretensão excluí-las, antes incluí-las na medida em que despontarem ao logo do processo de investigação. Em todo caso, tanto na perspectiva de Peignot (1802) como naquela de Otlet (1934), a noção de "cultura impressa" se adequa, em sua amplitude, à totalidade da expressão epistêmica da Bibliologia projetada por tais autores em sua relação direta com as transformações da Modernidade.

\section{A imprensa na cultura: achegas à "cultura impressa"}

Após os eventos ocorridos no espaço-tempo que provocaram mudanças nas práticas de registro do conhecimento, surge no século XV aquele que se tornou presente na Modernidade, o livro impresso. Era uma época favorável ao seu aparecimento - como indica Barbier (2008), no Quatrocentos, pessoas adquiriram familiaridade com a escrita e com modelo de livro manuscrito por causa do crescimento das universidades, sendo o conhecimento, que na Alta Idade Média esteve restrito aos coléricos, atravessado um processo de expansão para além dos mosteiros. Foi quando ocorreu a chamada "laicização" do saber e da técnica de reprodução dos livros. Soma-se a isso, o espírito inventivo do homem do século XV:

Pequenos grupos de inventores e de empreendedores trabalhavam sobres problemas técnicos de todo o tipo: papelaria, fabricação de espelhos, polimento de pedras preciosas, armas de fogo, aperfeiçoamento de estampagem dos volumes, pesquisa e um novo método para multiplicar textos" (BARBIER, 2008, p.114)

De acordo com Barbier (2008) e Martins (2001), mesmo que tenham aparecido dúvidas acerca da autoria da invenção, o mais adequado é atribuir a Gutenberg a responsabilidade pelo aparecimento da imprensa na Europa. Pouco se conhece sobre sua vida. Sabe-se que este se chamava "Johann (ou Henne) Genlfeisch zur Landen, natural de Maiença, dito Gutenberg, nome da insígnia da casa em que nasceu. [...]” (BARBIER, 2008, p. 119). Fora filho de Friele Genlfeisch, um burguês local, ourives e conselheiro do arcebispo. McMurtrie 
(1982) conta que em Estrasburgo Gutenberg aprendera o ofício de seu pai e trabalhara num negócio de espelhos. Provavelmente essas experiências o ajudaram a inventar os tipos móveis de metal maleável.

O que se pode dizer da adaptação-inovação de Gutenberg, na qual veio a constituir a base do que se passou a tratar como cultura impressa, é que o invento criou um novo modo de fabricação do livro, a tipografia. O processo envolvia o uso de uma máquina de prensar (similar as que eram usadas na agricultura) e caracteres moldados em metal (tipos). Era necessário organizar os tipos de metal numa moldura acordo com o espaço destinado ao texto, deixando espaços livres para ilustrações e demais elementos gráficos. O próximo passo era encaminhar os tipos diagramados para impressão sobre a folha virgem, depois, caberia montar o livro no formato códice. Essa era basicamente a estrutura desenvolvida por Gutenberg que foi acrescida posteriormente junto de outras práticas, tais como o emprego do códice em tamanho reduzido e a paginação. Mas a cultura impressa atravessa outras culturas, já que essa se relacionava agora, objetivamente, de modo diferente da Antiguidade filosófica, com a noção de conhecimento.

A "Bíblia de 42 linhas" é o grande marco do livro impresso, fabricado pela oficina tipográfica de Gunteberg e de seu sócio Johann Fust por volta de 1455. Mas não foram somente os escritos sagrados que se beneficiaram da nova técnica. $\mathrm{O}$ trabalho tipográfico, o processo minucioso de conjugar letra e ilustração, foi importante para, mais tarde, tornar conhecidas as descobertas científicas. Lucien Febvre e Henri-Jean Martin (1992) contam que no ano em que Copérnico publicava De resolutionibus orbium coelestium em 1543, Vesalio mandou imprimir em Basiléia sua obra De humani corporis fabrica libri septem. Ambas as obras viriam tornarse vultosas para as ciências da época. A primeira tivera importância por defender o geocentrismo, a segunda por ilustrar com xilogravuras a anatomia do corpo. Não foi somente Vesalio que se beneficiou com as ilustrações xilogravadas. Houve obras de botânica, zoologia e geografia, como por exemplo: Herbarum vivae eicones ad naturae imitationem, Historia stirpium e De ortu et causis sbterraneorum. "As suntuosas publicações por meio dessas xilogravuras encontram um público de amadores esclarecidos, guiados às vezes, talvez, em suas compras por preocupações que nada têm de científico" (FEBVRE; MARTIN, 1992, p. 392). Assim a cultura impressa torna-se parte de uma cultura religiosa e de produção do conhecimento científico, parte das engrenagens que movimentaram a chamada Revolução Científica.

Um ponto relativo à difusão das ideias impressas no contexto histórico-cultural merece menção, por causa do contexto religioso que se configurou a partir do século XVI. Os textos 
cristãos foram difundidos já no nascimento da impressa. Como já dito, a Bíblia foi a primeira grande obra impressa na Europa, e mesmo que em menor número que os impressos humanistas, as publicações religiosas não cessaram. Um evento na Alemanha de 1517 parece ter colocado os impressos religiosos no campo da disputa de ideias: a Reforma Protestante. $\mathrm{Na}$ "origem de cada grande episodio da Reforma, há um edital" (FEBVRE; MARTIN, 1992, p. 392). Lutero fixou um edital impresso na porta da Capela de Wittenberg contestando as indulgências, o que levantou discussões.

As teses de Lutero foram, então, traduzidas para o alemão, e se espalharam rapidamente. Tornaram-se conhecidas em aproximadamente quinze dias, com ajuda da imprensa. Mais tarde, em 1521, ocorreu outro episódio envolvendo os impressos. Circulou pelas cidades da Alemanha, o Édito de Carlos V que ordenava a queima dos livros de Lutero. Pode-se até imaginar que parte do público leitor tomou conhecimento da existência dos livros proibidos a partir do Édito. Na pequena guerra de publicações, ainda ocorreu o caso de terem arrancadas as bulas de Clemente VII dos muros de certa catedral, sendo substituídas por denúncias ao Papa (FEBVRE; MARTIN, 1992). A disputa "termina, em 1534, no caso dos famosos editais contra a missa impressos por Pierre de Vingle em Neuchâtel, dos quais o rei encontra exemplares até na porta de seus apartamentos" (FEBVRE; MARTIN, 1992, p. 411).

Os pequenos livros também tiveram uma participação importante para a difusão de Lutero.

\begin{abstract}
Lutero ao mesmo tempo em que responde em latim aos teólogos, seus adversários, escreve em alemão, a fim de atingir um público maior, seu apelo À nobreza cristã da nação alemã (1520) e multiplica os sermões, os livros de edificação, as obras de polêmica na lingua de seu país. Das impressoras de Wittenberg saem, logo reimpressas em toda a Alemanha, os livrinhos manipuláveis, leves, mas de tipografia clara, com títulos nítidos e sonoros, inscritos em belos equadramentos enfeitados À maneira alemã, sem data nem endereço do editor, mas trazendo, no alto da obra, o nome sonoro, Martinho Lutero. (FEBVRE; MARTIN, 1992, p. 412)
\end{abstract}

Provavelmente houve outros momentos na história humana em que a imprensa teve participação fundamental na disseminação de ideias. Contudo, para uma pesquisa que propõe investigar as aproximações do pensamento comeniano com a cultura impressa, consideramos adequada uma revisão que apontasse o aspecto da disseminação nas Ciências e na Reforma, pois Comenius transitou por esses dois universos, o que será tratado no capítulo a seguir.

Pôde-se conhecer, em linhas gerais, o significado da cultura impressa mediante os norteadores traçados. A cultura impressa surgiu num período favorável às invenções, mas como 
qualquer outra, se constituiu na dinâmica de apropriação das culturas herdadas, como o uso de técnicas anteriores para inventar a escrita com os tipos móveis. Reconhecidamente no campo historiográfico, a imprensa representou um dos grandes inventos relacionados àquilo que se passou a considerar como civilização moderna, o que levou a afirmações como: "na história da cultura humana não há acontecimento que tenha a importância do invento da impressão com tipos móveis" (MCMURTRIE, 1982, p. 159).

\section{Um pensamento dentro da cultura impressa: elementos da vida e da obra de Comenius}

Como já identificado, seguimos o percurso biobibliográfico de Comenius, ou seja, o percurso da vida que existe em diálogo com e para o mundo. O objetivo foi avançar no território das possíveis experiências da cultura impressa para chegar ao debate filosófico, no plano bibliológico, que estabelece a relação entre cultura impressa, filosofia e Modernidade a partir de Comenius.

A vida aconteceu para Comenius em território checo nos fins do século XVI. Ele nascera no estado da Morávia em 28 de março de 1592, provavelmente nas imediações de Uherský Brod (vau húngaro), na aldeia de Nivnice. Os primeiros anos de sua infância foram no centro de Uherský Brod com sua família. Seu pai se chamava Martin Komenský (originário de Komna), era membro da burguesia checa e adepto da comunidade protestante da União dos Irmãos Morávios (Unitas Fratrum), comunidade que a assumiu um lugar de destaque no cenário político-religioso da Morávia. Significava a resistência protestante, frente à Contrarreforma. Sua origem recupera os primeiros enfrentamentos ao catolicismo romano, figurado por Johann Hus. Este fora reitor da Universidade de Praga (situada na Boêmia) e um dos precursores da Reforma Protestante, quase um século antes de Lutero e Calvino. Dizia que "só Cristo é o cabeça da Igreja, e a Bíblia a única autoridade em questão de fé” (COVELLO, 1999, p. 15). As ideias de Johann Hus o levaram à fogueira em 1415, mas os remanescentes do movimento hussita levaram a frente seus princípios, vindo surgir a União do Irmãos Morávios. Mantin batizara seu filho com nome de Johann Comeniusı, de modo que "a tradição tende a interpretar

\footnotetext{
${ }_{1} \mathrm{O}$ autor aparece em língua checa como Jan Amos Komenský. No Brasil se conhece duas formas do nome: João Amos Comênio (português) e Johann Amos Comenius (latim). Optou-se pela forma latina em função do catálogo de autoridades da Biblioteca Nacional.
} 
este nome de batismo atribuído a denominação Jan como sendo devido a Jan Huss, o grande inspirador daquela irmandade [...]" (KULESZA, 1992, p. 23).

Sobre Morávia do fim do XVI, sabe-se que esta era parte do império austríaco Habsburgo, juntamente com a Boêmia, Silésia e as Lusácias. Segundo Cauly (1995, p. 24), a Morávia era uma terra de liberdade e prosperidade "[...] onde coabitava, sem conflitos manifestos, católicos, luteranos e calvinistas, anabatistas oriundos da Suíça e da Áustria, antitrinitários, calistinos e Irmão Checos [...]”. A causa desse cenário provavelmente estava na politica religiosa conciliatória adotada pelo rei da Casa dos Habsburgo, Rodolfo II. Ele que representava um império declaradamente católico fora mais flexível com os protestantes checos. Permitiu-lhes a realização de cultos e concedeu direitos fundamentais aos não católicos através da "Carta da Majestade" (1609). Contudo, a Morávia enfrentava problemas com os otomanos nos limites com a Hungria. Enquanto Rodolfo II desfrutava da esplendorosa Praga, capital do Império na Boêmia, ouvia certos rumores de conflitos nas proximidades de Uherský Brod. Cauly (1995) narrou que no ano do nascimento de Comenius, teve início um conflito com os turcos que só terminou em 1606, o que afetou a vida do jovem Comenius. Seu pai faleceu na época das invasões, em 1602 - se bem que não sabe precisamente se fora por causa da guerra - tempos depois, a pestes que era comum durante as guerras vitimou sua mãe, Anna, e suas duas irmãs. Órfão, Comenius teve que ficar sob a tutela de sua tia Zuzanna em Stráznice; local com fronteiras menos seguras que Uherský Brod. Isso levou o jovem Comenius a procurar abrigo na casa de seu tio em Nivnice. (CAULY, 1995; KULESZA, 1992).

O que também se pode dizer sobre a infância de Comenius é que ele esteve imerso na cultura dos Irmãos Morávios, que se caracterizava pela moral austera, o apreso pelas Escrituras e a valorização da língua materna. Dos tempos em Uherský Brod “é verosímil que Comenius tenha frequentado a instrução primária na escola paroquial”' (CAULY, 1995, p.31), pois ainda que a Morávia fosse oficialmente católica, com um colégio jesuíta instalado, a liberdade concedida aos protestantes permitia que os Irmãos Morávios educassem seus filhos na sua própria escola paroquial. Não é estranho que Comenius “[...] tenha podido aprender a ler e a escrever graças aos alfabetos e catecismos que os Irmãos publicavam para as crianças [...]"(CAULY, 1995, p.31). Segundo Cauly (1995) é provável que Comenius tivesse tido contato com livros ilustrados de salmos, impressos na tipografia dos Irmãos Morávios, que foi posta em funcionamento nas últimas décadas do século XV. Foi no seio da religião checa que se trabalhou entre 1579 e 1593 na tradução da Bíblia para a língua checa, a chamada "Bíblia de 
Králice”, na ocasião impressa em uma tipografia clandestina no castelo de Králice. "Foi esta Bíblia (da qual seguramente a família de Comenius tinha um exemplar) que acompanhou o jovem Komenský na sua instrução primária” (CAULY, 1995, p.33).

Comenius continuou a ser instruído quando esteve com sua tia em Stráznice, porém o ensino foi interrompido no momento de sua mudança para Nivnce. Lá sob a tutela de seu tio, um artesão moleiro, faltou-lhe a educação formal, contudo, Comenius pode conhecer a arte de oficio na qual praticava seu tio, iniciando-o nas atividades manuais. Comenius retornou ao ensino formal tardiamente em 1608, indo para a escola de Prerov, onde ingressou nos estudos secundários. Constituía um ambiente pacífico e de florescimento, onde Carlos de Zerotin encaminhava com louvor a reforma da educação protestante. O empenho de Zerotin era por uma escola ao gosto do humanismo que conhecera em Basiléia, fazendo distinção ao ensino jesuíta que tradicionalmente valorizava a retórica, a dialética e o latim (CAULY, 1995; KULESZA, 1992). Segundo Cauly (1995) Prerov se diferenciava por oferecer uma formação de carácter intelectual, moral e profissional. Esse último e peculiar aspecto inseriu novamente Comenius no ambiente das artes de ofícios. Na escola alguns alunos "trabalhavam na tipografia, enquanto outros encadernavam livros ou cortavam árvores [...]” (CAULY, 1995, p. 42).

Nesse ponto do percurso já percebemos indicativos de um território cultural, donde se decorrem práticas e apreensões, receptivo à cultura impressa (e onde Bibliologia e Modernidade se entrecruzam). Comenius teve contato desde cedo com obras impressas e veio a frequentar uma escola que introduzia os alunos na arte de imprimir livros. Vejamos agora como foi sua experiência na juventude e na fase adulta, a partir do ingresso na universidade de sua atuação como autor de livros.

Em Prerov, Comenius esteve sob a tutela do próprio reformador da escola, Carlos Zerotin, que após o ensino secundário o encaminhou para o pastorado, o que o fez Comenius ingressar nos estudos teológicos em 1611 na universidade alemã de Herbon. Instalada na cidade de Nassau, Herbon pretendia ser centro do humanismo protestante, com uma teologia inclinada ao calvinismo, e aberta aos estudos das ciências. Lá, Comenius teve contato com as obras de Andrea, Campanella e Vives, ouviu as preleções de Fischer, e conheceu o enciclopedista Alsted. Ali também viu expostas as teses que proclamaram a reforma do ensino de Ratke. Nessa época Comenius iniciou a Linguae bohemicae thesaurus2, um léxico capaz de auxiliar na tradução do

2 Segundo Kulesza (1992) e Cauly (1995) essa obra foi perdida no incêndio de Leszno em 1656.

InCID: R. Ci. Inf. e Doc., Ribeirão Preto, v. 8, n. 1, p. 4-23, mar./ago. 2017. 
latim para o checo. Desse modo, Comenius se comprometeu com o vernáculo, como bem apreendera com os Irmãos Morávios. Saindo de Herbon e passando brevemente por Amsterdã, Comenius matriculou-se em outra praça forte do calvinismo, a universidade de Heidelberg, onde permanecera nos anos de 1613 e 1614. Ali ele se empenhou para escrever Amphithetrum universitatis rerum, obra que pretendia compilar o conhecimento humano (CAULY, 1995; KULESZA, 1992). "Já ensaiando desenvolver a veia enciclopédica de Alsted” (KULESZA, 1992, p. 13).

Comenius retornou ao território checo após os estudos universitários e foi lecionar latim na antiga escola de Prerov. O ensino do latim consistia em memorizar textos indecifráveis e regras gramaticais pouco compreensíveis para os alunos. Ao identificar esse problema, Comenius seguiu em busca de um método facilitado para o ensino do latim, escrevendo "Os preceitos para uma gramática mais fácil” (Grammaticae facilioris praecepta). A obra foi publicada em Praga em 1616, tornando-o conhecido na Europa. Comenius não abandou suas atividades religiosas, adquiriu respeito entre os Irmãos sendo ordenado o pastor, o que lhe acrescentou o nome de Amós, em referência ao profeta bíblico. Foi também após seu regresso à terra natal que Comenius se casou (KULESZA, 1992; CAULY, 1995).

O prestígio de Comenius veio com sua obra de gramática e a ordenação a pastor nos Irmãos Morávios. Então, deram-lhe o posto de reitor da escola em Fulnek (por volta de 1618). A cidade situava-se ao norte da Morávia, na fronteira com a Silésia. Comenius conhecia o idioma alemão e parecia ser uma pessoa indicada para trabalhar na conciliação entre os moradores de diferentes origens que lá habitavam (KULESZA, 1992; CAULY, 1995). Nessa época, Comenius escreveu a "Carta ao céu" afirmando que "a paz é uma coisa santa e sua pureza não deve ser profanada pelo recurso a um qualquer meio" (CAULY, 1995, p. 68).

Acontecimentos no Império desestabilizaram a vida do pastor e reitor de Fulnek. O rei Rodolfo II foi sucedido por seu irmão Matias, que já idoso preferiu coroar em seu lugar o arquiduque Fernando, em 1617. O novo rei deveria se comprometer com a "Carta da Majestade", que dava direito aos protestantes, mas seu histórico de apoio a recatolização gerava desconfianças. Fernando II foi confirmando sua posição ao lado do catolicismo e com a “Defenestração de Praga" teve início uma longa guerra politico-religiosa, a Guerra dos Trinta Anos, o que fez de Comenius um peregrino pela Europa (CAULY, 1995). 
Em 1622 foram expedidos mandados de prisão a líderes protestantes sob o consentimento de Fernando II, isso forçou Comenius a abandonar o trabalho pastoral e fugir. Ele encontrou abrigo momentâneo no castelo de Zerotin, na Boêmia, porém sua esposa e duas filhas não puderam acompanha-lo, que por permanecerem em Fulnek foram vítimas da epidemia. Nesse momento conturbado Comenius escreveu "Labirinto do Mundo e Paraíso do Coração" (1623). Segundo Cauly (1995) o enredo aproximava Comenius das utopias, como a "Cidade do sol" de Campanella, e tratava da desesperança da alma num mundo religioso caótico e em contradição. Ainda no exilio3 Comenius deu inicio a "Didactica Checa" (1627) que mais tarde veio a se tornar a Didactica Magna, uma das mais representativas obras da educação moderna. O objetivo de Comenius com a "Didactica Checa" era de dispor em língua materna os termos para a implementação de uma educação mais justa e democrática em todo o território checo. (CAULY, 1995; COVELLO, 1999). A Didactica Magna veio a ampliar essa ideia para além a Educação Checa.

A Didactica Magna que foi concluída por volta de 16384 e tinha a intensão de ser um grande tratado da Educação em língua vulgar: "O Tratado da arte universal para ensinar tudo a todo". Ele propunha uma educação que pudesse formar a todos independentemente do sexo e da condição social, considerando o saber reunido e dimensão moral, prática e intelectual da Educação. Seu método era organizado e sistemático. As escolas deveriam ser agrupadas conforme a faixa etária do aluno, de modo que fosse ensinado primeiro as coisas mais fáceis e por último as mais difíceis. Comenius também dizia que eram necessários manuais e livros didáticos ao alcance dos professores e alunos.

Na Didactica Magna Comenius comparou os materiais didáticos aos tipos móveis da oficina tipográfica, estes devem ser "propositadamente preparados para que, com a sua ajuda, as coisas a aprender se imprimam nas mentes com pouca fadiga" (COMÉNIO, 1985, p. 458). Comenius também tomou outros elementos da realidade para sistematização, às vezes ligados ao trabalho manual e as tecnologias da época, como por exemplo, o jardineiro, o artista pintor, e o relógio. O carácter sistemático apresentado na Didactica Magna fez com que estudiosos inserissem Comenius no despontar da Modernidade. Cauly (1995) comentou que alguns se referiram a Comenius como o "Descartes" da Educação, outros como o "Galileu".

з Kulesza, 1992 e Cauly 1995 confirmam que durante o exilio na Boêmia, em 1627, Comenius tive contato com Didactica de Elias Bodin, o que serviu de inspiração para inciar no mesmo ano a Didactica Checa.

4 Acredita-se que este seja o ano de conclusão da obra, mas é desconhecida a publicação desde ano, o que se sabe é que versão na qual temos acesso atualmente corresponde à publicação de 1657. 
Outra importante obra no contexto educacional foi "Porta aberta das línguas" (Janиa lunguarum reserata, 1631), que era uma espécie de manual "trilíngue" para o ensino do latim, com páginas divididas em três colunas, de modo que frases em latim ficavam em paralelo com frases correspondentes ao idioma materno. Dado seu aspecto "trilíngue", a "Porta aberta das línguas" se tornou uma das obras comenianas mais celebradas na Europa durante o século XVII (CAULY, 1995; KULESZA, 1992). A "Porta aberta das línguas" foi composta no tempo em que Comenius se instalou na Polônia, onde lecionou no ginásio de Lesno. A "pansofia" foi outro projeto de Comenius iniciado na década de 30, o qual se inclui quatro textos: Praeludia (1637), "Precursor da pansofia" (Prodromus pansophie, 1639), "Esclarecimento da empresa pansófica" (Dilucidatio, 1639) e "Apresentação da pansofia" (Pansophie diatyposis, 1643). A "pansofia" consistia na construção de um sistema universal que agrupava os saberes produzidos pela humanidade, "tecendo um elo vivo entre todos os campos da experiência e territórios do conhecimento" (CAULY, 1995, p. 209). A ideia conquistou um grupo de letrados ingleses, especialmente Samuel Hartlib, que uniu esforço para levar Comenius para a Inglaterra e lá tocar o projeto pansófico que prometia a elevação do homem num mundo em renovação. Assim, em 1641, Comenius se transferia para Londres (CAULY, 1995; COVELLO, 1999).

Apesar da receptividade da "pansofia" em Londres, Comenius ficou preocupado com as agitações internas e a revolta dos irlandeses. Assim, aceita o convite do rei da Suécia de preparar manuais escolares para uma reforma educacional, de modo que seguiu para Elbing. A caminho, Comenius passa pela Holanda, onde é recebido por alguns amigos, e fica brevemente em Leiden. Alguns destes frequentavam o círculo de René Descartes e lhe arrumaram um encontro. A conversa entre Comenius e Descartes durou cerca de quatro horas. Existiam pontos de divergência entre os pensadores. Os estudos de Comenius possuíam o carácter universalista e mantinham ligações estreitas com a ciência e religião, já Descartes intentava pela disjunção dessas; o método comeniano de aquisição de saber se explicava pela empiria, enquanto o cartesiano se fundava na razão. Apesar das diferenças, a conversa terminou em tom amigável (KULESZA, 1992; CAULY, 1995).

Após transitar pela Holanda e Suécia, Comenius se instala em Saros-Patak com objetivo duplo, a saber, fortalecer a aliança entre os Irmãos Morávios e os calvinistas, e, conduzir a reforma escolar na região norte da Hungria. Em 1653, juntamente com o projeto de reforma escolar cuja proposta era implementar a pansofia, Comenius dedicou tempo para redigir "O mundo sensível em imagens" (Orbis sensualium pictus), que foi publicado somente em 1658; 
obra que se tornou um marco no tocante ao livro didático ilustrado. Tratava-se de uma espécie de enciclopédia, que associava sistematicamente o texto à imagem. Havia uma legenda ao lado das ilustrações indicando o significado das coisas. Ao sair da Hungria 1654, Comenius não encontrou paz nas conhecidas terras polonesas, é então que decide viajar para Amsterdã (KULESZA, 1992; CAULY, 1995; COMÉNIO, 1957). Desse ponto em diante foi que Comenius conseguiu finalmente publicar a Didactica Magna. Com o apoio da burguesia holandesa Comenius reuniu suas obras didáticas completas: Opera didactica ominia, impressa 1657. O conjunto inclui o célebre texto da Didactica Magna e os demais pedagógicos escritos da época em que esteve em Leszno, Elbing e Saros-Patak. Os anos que se seguiram em Amsterdã foram os últimos da vida de Comenius (KULESZA, 1992; COVELLO, 1999). O “pai da pedagogia moderna" (é assim que Oliver Cauly o nomeia) encerrou seus últimos anos sem muitas preocupações, mas sem poder regressar a sua terra natal.

Pelo que vimos da fase adulta de Comenius percebemos que houve um estreitamento dos laços que o ligavam à religião protestante, e um volume de produção bibliográfica significativo apesar das intempéries da Guerra dos Trinta Anos. Comenius se tornou pastor e defensor da paz, além disso, conviveu no círculo do humanismo europeu e se apropriou das lições de enciclopedistas como Aslted. Foi transitando por esses territórios culturais que Comenius elaborou ideias e compôs obras. Se nós vimos anteriormente que ambos os territórios foram um solo fértil para a cultura impressa no aspecto da difusão, podemos imaginar um Comenius exposto à experiência cultural dos impressos.

Curiosamente o percurso biobibliográfico de Comenius nos indica uma relação entre a experiência de viver no mundo (vivendo) e de ser no mundo (sendo) em manifestação da própria experiência. Comenius viveu no mundo e foi no mundo, enquanto protestante, erudito, professor, e autor de obras, sendo que essa última categoria o coloca no campo da manifestação das experiências e ações de posição e oposição no espaço-tempo, uma vez que a obra bibliográfica é também manifestação.

Podemos chegar a esse raciocínio quando observamos que Comenius "sendo" no contexto de disputas entre católicos e protestantes, escreveu críticas ao caos religioso, ou quando "sendo" professor tomou as experiências negativas para propor uma educação democrática e sistematizada por meio da Didactica Magna. Não estranharíamos, então, se Comenius tivesse apreendido, pela experiência, conhecimentos empíricos de uma cultura (modos de vida) da técnica de imprimir e da difusão de ideias impressas, a qual esteve imerso 
durante sua infância e fase adulta. O Comenius que dizia na Didactica Magna que as coisas a aprender se imprimem na mente atinge um elo entre as noções de "impressão" e "verdade", o diálogo entre Filosofia e a empiria dos saberes bibliológicos; sua filosofia se torna, pois, o ponto de encontro clássico entre Bibliologia e Modernidade, uma das fronteiras epistemológicas centrais entre o pensamento moderno e as ciências dedicadas a pensar os registros do conhecimento.

\section{Considerações finais: Comenius no técnico-espaço da cultura impressa}

Podemos, a partir da investigação epistemológico-histórica, perceber que a cultura impressa constitui uma estrutura simbólica de formação e conformação do pensamento comeniniano. Falecido em 1670 e sepultado em Naarden, Comenius participa de um tempoespaço profundamente transformado pelos inventos bibliológicos e pela propagação de ideias através dos impressos. Desde cedo frequentou o círculo protestante dos Irmãos Morávios, que teve em seu poder uma tipografia para imprimir a "Bíblia de Kralice" (primeira tradução completa para o idioma tcheco da Sagrada Escritura).

Nos tempos de Comenius parecia não haver restrições para essa comunidade no tocante à publicação e à circulação de livros; deixavam-se livros à mão dos filhos da Morávia. O jovem Comenius provavelmente teve contato não apenas com os livros impressos, mas também com certa tipografia da escola em Prerov. Na fase adulta ele esteve entre professores dedicados ao projeto enciclopedista, e mais tarde deu o tom enciclopédico em seu projeto educacional, com o objetivo de "ensinar tudo a todos". Todos esses elementos parecem inserir a pedagogia comeniana na biografia de um Comenius "culturalmente bibliográfico".

As questões estritamente referentes à fillosofia da educação são, no escopo sócio histórico, também vinculadas a uma filosofia do livro ou filosofia bibliológica (no sentido tanto peignotiano como otltetiano). $\mathrm{Na}$ pansofia comeniana, às análises do mundo sensível dependiam, como observado, de uma enciclopédia; toda a prática pedagógica, seja o ensino teológico, seja a aprendizagem das línguas, era baseada estruturalmente em um elemento mediador, o livro, e explorar seus potenciais de construção e suas possibilidades de propagação eram fundamentais para a realização filosófico-pedagógica moderna. 
Em termos epistemológicos, podemos afirmar a existência, em Comenius, de uma “impressão histórica" da práxis da cultura impressa comum na mentalidade dos primórdios da Modernidade. Em outras palavras, uma "ciência do livro" (a Bibliologia nascitura), impulsionada pelas transformações sócio técnicas, passa a ser, a partir dali, a força-motriz de um conjunto de mutações que chegarão até a Revolução Industrial no século XVIII.

Reconhecemos que a literatura sobre estas grandes mudanças históricas, no escopo da história das técnicas e da história da ciência, por exemplo, já abordou exaustivamente tais fatos. O que procuramos concluir, no plano epistemológico biblioteconômico-informacional, é que, através de um percurso bio-bibliográfico, pode-se perceber pontualmente o desdobrar desses fatos, não apenas como manifestações aplicadas, mas também como fonte para o desenvolvimento de uma abordagem teórica que tem, no modelo filosófico propiciado pelo mundo do livro (que está diretamente ligado, por exemplo, a um novo conceito de liberdade, vinculado às práticas de expressão e impressão na Modernidade), uma influência epistemológica fundacional. Em outras palavras, a partir de Comenius, percebemos o alvorecer de um novo ethos, teórica e socialmente fomentado pela cultura impressa.

\section{Referências}

ABBAGNANO, N. Dicionário de Filosofia. 5. ed. São Paulo: Martins Fontes. 2007.

BARBIER, F. História do livro. São Paulo: Paulistana, 2008.

BURKE, P. Problemas causados por Gutenberg: a explosão da informação nos primórdios da Europa moderna. Estudos Avançados, São Paulo, v.16, n. 44, jan./abr. 2002.

CAULY, O. Comenius: o pai da pedagogia moderna. Lisboa: Instituto Peaget, 1995.

COMÉNIO, J. A. Didactica magna. 3. ed. Lisboa: Fundação Calouste Gulbenkian, 1985.

COVELlo, S. C. Comenius: a construção da pedagogia. São Paulo: Comenius, 1999.

DARNTON, R. O que é a história do livro? In: cultura e revolução. São Paulo: Companhia das Letras, 1990.

EISENSTEIN, E. A revolução da cultura impressa: os primórdios da Europa moderna. São Paulo: Ática, 1998.

FEVBRE, L.; MARTIN, H. J. O aparecimento do livro. São Paulo: Hucitec, 1992.

FREIRE, P. Pedagogia da autonomia. 46. ed. Rio de Janeiro: Paz e Terra, 2013. 
GADOTTI, M. História das ideias pedagógicas. 8. ed. São Paulo: Ática, 2003

GASPARIN, J. L. Comênio: a emergência da modernidade na educação. Petrópolis: Vozes, 1998.

HUISMAN, D. A cultura humana. In: Compêndio moderno de filosofia. Rio de Janeiro; São Paulo: Freitas Bastos, 1966.

KULESZA, W. Comenius: a perspectiva da utopia em educação. Campinas: UNICAMP, 1992.

A escola da infância. São Paulo : Unesp, 2011.

MARTINS, W. A palavra escrita: história do livro, da imprensa e da biblioteca. 3. ed. São Paulo: Ática, 2001.

MCMUTRIE, D. O livro: impressão e fabrico. 2. ed. Lisboa: Fundação Calouste Gulbenkian, 1982.

OTLET, P. Traité de documenatation: le livre sur le livre: théorie et pratique. Bruxelas: Mundaneum, 1934.

PEIGNOT, G. Dictionnaire raisonné de bibliologie. Paris: Chez Villier, 1802a. tomo I Paris: Chez Villier, 1802b. tomo II

Artigo submetido em: 16 dez. 2016

Artigo aceito em: 06 abr. 2017 